Published in Sport, Ethics, and Philosophy, 13, 1 (2019): 94-106.

https://doi.org/10.1080/17511321.2017.1388272

\title{
Intensity and the Sublime: \\ Paying Attention to Self and Environment in Nature Sports
}

\author{
Leslie A. Howe
}

In a recent paper, Kevin Krein (2015) argues that the particular value of nature sports over traditional (urban) sports is that they offer intensity of sport experience in dynamic interaction between an athlete and natural features, but without competition. Thus, he denies that intensity in such sports is derived from the competitive conflict of individuals, as well as denying that nature sport derives its value from a putative internal conflict within the athlete who carries out the activity. What merits further analysis is the question of what exactly constitutes the intensity, whether the subject is traditional or nature sport. This is because 'intensity', while attributing force to an experience, does not by itself tell us anything else about the nature of that experience: its content, source, sensory or emotional characteristics, or even its style. I shall argue in the following that intensity in certain kinds of kinaesthetic activities is the outcome of several components, especially the problematic relationship between attention and reflection. I shall then apply this analysis to the narrower case of nature sports. In doing so, I shall respond to a number of criticisms offered by Krein with respect to competition and self-conflict, before examining the concept of the sublime and its apparent influence on Krein's reliance on its special kind of intensity to characterise the value of nature sport. I shall then argue that a preference for sublimity raises some awkward questions for the proponent of nature sports.

\section{Intensity}

Sporting experiences and events may be described as intense or as lacking in intensity. But what exactly does this mean and how can these things be so described? As usual, dictionary definitions cast only limited light on the issue; the Oxford English Dictionary only tells us that a quality or condition is intense if 'raised to or existing in a strained or very high degree; very strong or acute; violent, vehement, extreme, excessive, etc.' Let us then consider the sorts of situations that we might ordinarily describe as intense and that may have relevance to our present concerns:

1. A powerful, overwhelming physical sensation, e.g., pain or pleasure.

2. A single activity that completely fills one's attention, e.g., an intricate task that will fail if not done correctly, or which is simply sufficiently satisfying as to exclude other considerations, such as writing or other creative work.

3. Events that have a complex set of elements, all of which make demands on one's 
Intensity and the Sublime 2

attention, e.g., a multimedia performance or a fast-paced team sport.

4. Situations where all involved are participating with high emotion or at extreme levels of exertion, e.g., rescue operations, many sporting events, or even a disastrous dinner party or family gathering.

5. Solitary activities accompanied by strong emotions, such as fear or sadness, where the physical expenditure is relatively mild, e.g., crossing a high footbridge or attending a graveside.

6. Experiences of overwhelming environmental awe, possibly terror and aesthetic grandeur; in other words, of the sublime in natural settings, such as high mountains, powerful rivers, etc.

7. A closely contested struggle between skilled opponents.

No doubt there are further possible candidates (e.g., colours and sounds can be described as intense), but this list alone generates some pertinent questions. The first thing to note is that intensity can be attributed to both solitary and social activities. Just as importantly, it applies equally to the physical, emotional, and phenomenological: we can identify as intense our experience of physical stimuli or confrontation, our emotional response to a physical or social situation, and the experience of phenomenological fullness, whether it is an undifferentiated openness to or an incisive attention to that phenomenal detail. While the examples enumerated above indicate that intensity can be experienced over a span of human activities, our concern here is with the opportunities afforded by sport, which could, in fact, offer intensities of any of these types and in multiple combinations.

Sport, however, is not a uniform set of activities. Traditional or urban sports and nature-oriented sports have some important differences; so, too, do individual and team sports or solitary and social sport activities. How intensity is experienced in these different situations might be expected to vary since the elements from which it arises vary.

For present purposes, I will concentrate on one kind of intense experience, namely, that of being fully present in the flow of activity and movement. This kind of experience presents some difficulties for analysis: it is in important respects immediate rather than reflective and this invites ambiguities in its characterisation. The presence of experience to self seems to involve an absence of self in the experience, but these oddities of description are, I think, resolvable through analysis of the place of attention and reflection in these kinds of flow intensity experiences. Such an explanation is more readily available if the self that experiences is conceived in terms of an embodied intentionality rather than a more distanced mode of reflection. Thus, for example, Suzanne Jaeger, defending the concept of presence in theatre and dance, relies on Merleau-Ponty to characterise it as an 'openness to alteration in the unity of a bodily schema, that fully embodied activity of synthesis and balance between richness and clarity which constitutes our perceptual experiences' $(2006,137)$. The kind of phenomenon she is referring to is one that differs from sport to the extent that an essential element in it is the ability to project that presence outward; while hardly unknown to sport, it is here less 
Intensity and the Sublime 3

centrally defining than in the performing arts. Nevertheless, while sport often orients itself toward show though it is not inherently so directed, a large proportion of sport activity is social rather than solitary. Moreover, whether solitary or social, sportspersons must be concerned with action as it concerns self (what movement is being performed) and to key elements of the environment within which they act: in relation to what or whom. Several consequences of this follow for flow intensity ('on') experiences. First, partners and opponents in play constitute part of the intentional environment to which one makes oneself present (thus, an opportunity) and, second, they also constitute an obstacle to attaining this state. This is because intensity demands attention.

\section{Attention and Reflection}

To be fully present in some activity, it must have my undivided attention-no distracting mental chatter to break my absorption in the experience of it. This is where the description can seem contradictory: to be fully present I also in some sense must be absent; that is, I am not myself present to myself as an object of reflection even though I am keenly aware of what I am doing as a subject. Attention here is a matter of removing the distance between agent and action: I am all there, in it.

This is by no means an unattainable condition in social sports, but sports that involve ranking or confrontation insert a need to consider ourselves as objects as well, to reflect on our own activity as other than ourselves. So do solitary sport activities, especially when we are learning them, but if I need be less concerned with how my performance measures against someone else's, or do not have to put up with the unsolicited 'appraisals' of others (i.e., trashtalk, banter, and the like) my opportunities for pure attention may be enhanced.

As should also be evident from the above list of sources of intensity, not all of it is either useful or desirable. Sporting practice finds us both seeking out intense experiences and trying to keep that intensity under control. In ordinary life, while experiencing intense pain, for example, we often seek to distract ourselves from the sensation by thinking of something else, perhaps something pleasant, more often by attempting to concentrate on something complex. Thus, we fix attention elsewhere, often by means of reflection, attempting to fill as much of our phenomenological space as possible with alternate content. Here, we use reflection to deaden intensity. In sport, on the other hand, such deadening may be counterproductive. For example, before an important race or game an athlete may be overwhelmed by the enormity of the occasion and unable to concentrate on the immediate task. Going through a detailed check of equipment or warm up routine distracts from the negative effects of these sensations by rendering the situation ordinary or at least manageable, while the studied routine of relevant procedures allows them to keep attention on the task ahead. This is using reflection to get reflection under control. The intensity from which the athlete suffers in this case is not simply some inchoate wash of undifferentiated 'feeling', but a set of specific, if perhaps incompletely formulated, apprehensions that generate a further set of physical symptoms: fear of losing, of looking ridiculous, 'letting others down', forgetting the race plan or team strategy, 
Intensity and the Sublime 4

worry about whether technique is good enough, etc. Reflection here is used to prevent a reflective dwelling on undesirable outcomes that threatens present concentration and thus is not being used to kill the intensity but to re-focus it on what must be done.

Flow is usually characterised in terms that suggest it is a form of immediacy, and immediacy and reflection are prima facie inimical. But flow is the consequence of a great deal of deliberate and reflective effort in training, including treating oneself and one's performances objectively; it is not a state of analytic obliviousness. Perfect movement doesn't simply happen but is a result of making a lot of correct choices because one knows how to do so. Movement flows because one is making the right choices and not reflecting on oneself making them. The perfect moment in activity isn't dumb genius but perfectly present attention, which is made effective by knowledge and judgement as well as physical activity.

These are the moments we aim for in sport, but they are not our constant companions. As suggested earlier, flow is not the only kind of intensity in experience that sport can offer. Intensity can also be experienced in the heightening of physical effort and of emotional commitment that occurs in competitive encounters. These need not be direct proximity or contact encounters; the same intensity can be experienced where participants compete in separation, or by turns. Here the struggle for the sportsperson is not just to have experiences of peak performance but to continue to perform under conditions of competitive stress, that is, in circumstances where opponents may be attempting to prevent directly or to subvert that performance, even as they contribute to the conditions that may produce it. The intent here is not to be deliberately contradictory, but to point out that our opponents are (ideally) our partners in performance: they present us with challenges to which we respond in one way or another.

For the spectator, intensity is in the clash; for the athlete it is in this, too, but first and foremost it is in the experience of challenge and response. That this is so, consider sports in which there is an illusion of non-intensity, e.g., rowing. Few non-rowers watch regattas and most non-rowers who do see only slow and graceful, calm, almost serene movement. For the rowers, it is mostly pain, nausea, noise, exhaustion, and the internal struggle not to quit-even when it also works perfectly. Intensity is felt in the total physical demand, in the mental determination to concentrate on precise technique, plan, and response to commands, and in the unforgiving awareness of every movement of body, crew, and boat: a phenomenological fullness of experience and presence in this one slice of existence.

Whether or not one experiences flow under these circumstances, one does experience intensity. Moreover, this intensity persists while one makes judgements that are directly about sport skills, say, about stroke rate, compensation for wind direction, holding off or mounting a challenge. One may also face judgements about whether one can continue with one's race plan. If one is 'on', these will be optimal for one's capacities and situation. But the less 'on' one is, the more chatter one may experience-the more doubt, confusion, and indecision. 
Intensity and the Sublime 5

Reflection drowns out one kind of intensity and brings its own. It isn't that one kind of experience is more intense than the other, but that flowing-intensity is more harmonious than the cacophony that accompanies kinetic breakdown. Intensity isn't lost but it changes to something that is less useful and less enjoyable for the participant. Our preference for flow states is understandable: they feel good and are symptomatic of sport mastery (or flatter us so), unlike those where we fight to regain control of our situation and have success in it-though we do gain a particular satisfaction at getting through these experiences. But our desire for intense experiences is not simply a desire for non-reflective states; it may also be a desire for meaningful decision-making.

\section{Reflection and Nature Oriented Sport}

Krein maintains that nature sports are significantly distinct from traditional sports in that the intensity that they are able to generate for their participants does not arise from a competitive situation, 'but purely from dynamic interaction between athletes and natural features' (281).

'In such sports, the athletes are fully immersed in their environment and due to the size and power of the natural features with which athletes interact, they are compelled to focus and react if they are to participate in the activity at all..... The intensity of nature sports comes from the fact that, in them, athletes interact with constantly changing features possessing awe-inspiring amounts of force and size. The nature of this interaction, rather than competition, is the source of intensity. In short, the size and power of natural features creates compelling opportunities to interact with them athletically, both mentally and physically, without the need for competition.' (Krein 2015, 282)

Clearly, environments such as these offer the potential for intense flow states; given the multiple variables in relation to which one must respond, these are also situations in which we may be called upon to make decisions with greater import than winning a race or scoring a goal. Consequently, the kinds of intense experience that may be desirable are ones where judgement is not blocked out. Decisions may also need to be made without significant time for reflection. This dictates a need for heightened levels of skill and knowledge in order for intense flow states to be achieved under conditions of potential danger, or at least more than a garden variety degree of inconvenience. On the other hand, it should also be admitted that significant intensity of experience (both positive and negative) is available to the lesser skilled as well, just in respect of the aesthetic qualities of the environment. Different varieties and contents of intensity may be experienced by participants in nature sports, both those that are comparable to those experienced by competitive athletes and those that are more focussed on aesthetic appreciation of landscape and movement through it for its own sake than on the exercise of skill.

Krein's discussion of the value of nature oriented sport over traditional sport seems to 
Intensity and the Sublime 6

include elements of both these sorts of intensity, although he maintains that a special value of nature sport is that it does not require competition. While I agree that it does not, Krein's discussion of the value of intensity-oriented nature sport suggests that the intensity derives in large measure from those sorts of engagement with natural features that require significant technical and physical skill combined with sound and informed decision-making. So what is unique about nature sport on this account is the experience of intense flow states (including the reflective flow involved in skilled decision-making) in relation to natural features and without inter-athlete competition.

To this point, Krein and I do not significantly disagree. He then, however, goes on to make the following assertions with respect to my discussion of self-competition in Howe (2008):

'There is, within Howe's position, a running argument that what really makes sport interesting is the fact that sometimes we get the best out of ourselves and sometimes we don't and that our performance is often the result of an internal struggle. I take the reasoning underlying her argument to be that traditional sport is interesting because of competitive human interaction, and competitive human interaction is interesting because it involves internal struggle in response to that interaction. Seeing that this is the case, it is a short step to the claim that, the same thing-internal struggle-must be what makes nature sports compelling' $(2015,282)$.

It is worth pointing out first that internal struggle is an indication of a sub-optimal situation. We do sport for a great many reasons, but an important one for those who pursue it out of love is the experience of intensive flow moments. The chatter of internal struggle is something we endure in order to eventually achieve those moments and, as with the example of Joe Simpson that I cited in the paper to which Krein refers, tends to break through when things are not going well. Whether it is a voice that urges us on or that insinuates failure, it is an internal conversation and a kind of intensity of experience that we would normally rather not have. It is true that coming through such an experience is an achievement, one that may ultimately teach us much about ourselves and improve future performance. And it is true that sporting activities of many kinds, both urban and nature-oriented, can constitute tests of our skills and of our resolve. Challenging ourselves is a way of improving our abilities in such situations. But we probably wouldn't persist in any of these activities if we didn't also get other joys from them. We seek to improve at least in part because doing so allows us to wring greater joy from the activity. The possibility of failure is an inseparable part of sport but that doesn't mean that we participate in it in order to experience failure. What draws us to sport is, among other things, the phenomenal experience of movement and, for nature-oriented sport, ${ }^{1}$ of (our self in) our surroundings.

${ }^{1}$ This specific term is explained in Howe (2012). 
Intensity and the Sublime 7

Sport is compelling because its rewards are great but not automatic. Yes, sometimes we get the best out of ourselves and sometimes we don't. Competition is a means, not an end in itself. It is desirable in large part because it can induce intensity of effort, extreme exercise of skill, revelation of self, and, occasionally, perfection of movement and fullness of phenomenal attention. It is an imperfect instrument, and only an instrument. As for internal struggle, this is a symptom of uncertainty that has no intrinsic connection with competition though this is one place in which it is frequently encountered, as it may in any situation of significant stress in which one must make meaningful decisions, including in nature oriented sport activities.

\section{Selves and Internal Struggle}

In the same paper, Krein also objects to my characterisation of inner struggle as a kind of competition. Insisting that 'competition' can only be applied to interactions between multiple individual humans, he maintains that the competing 'voices' we endure in these situations are 'drastically different from what we normally think of as selves,' not 'little, fully intact, selves that share a body'. 'These aspects of ourselves', he continues, 'have no conscious experiences, or if they do, they are not accessible to us. Nor does it make sense to say that they have their own desires, beliefs, and goals as do selves. A drive, a sensation, an affect, a motivation or a judgment is not a self, only a part of what makes up a self $(2015,275)$. Consequently, Krein insists that talk of competition in this respect can only be metaphorical. The objection, however, rests on a deep misunderstanding. I have claimed that competition occurs within the self, but this does not force us to accept a picture of squabbling homunculi, as Krein's caricature suggests.

If I have a number of desires or inclinations, not all of which can be satisfied, I must choose which of them to realise. I may do this by weighing them against each other, considering the advantages or disadvantages of acceding to this one rather than that, supposing that I have the leisure to do so. I may want the last piece of cake or to say what I really think to a colleague, but also know how I will come to regret either of these actions. Moreover, what I choose may well involve not just first order desires related to the immediate options but second order plans for myself-my larger projects of self. But which desires I choose to fulfill will define who I become.

Sport asks us to do this sifting of options and desires while under considerable physical, emotional, and temporal pressure. Sport is also, for the majority of its participants, considerably more voluntary than most other things we do. Thus, I may frequently find myself asking 'do I really want to do this?' This isn't a matter of one self asking another whether she wants to go on, but me asking myself whether the reward is worth the cost, and whether I am or want to be the self that wants this. The 'competition' here is metaphorical in the sense that there are not separate conscious entities battling it out, but real in the sense that I am, in effect, auditioning possible future selves, or versions of myself, that I might become-and only one can win. I cannot both quit and continue, but must decide now which one I will make of 
Intensity and the Sublime 8

my self. ${ }^{2}$

This is not to suppose that the self is fragmented, in the sense that we are in these situations at war with ourselves. But we do frequently have incompatible desires which we may describe as 'competing'. We do not need to suppose that we cannot reconcile conflicting desires into a coherent self-structure, but under conditions of high stress it may be uncertain which desire here, now, will be enacted. One of the features of highly skilled activity that produces perfect moments of flow intensity is that decision-making of this sort is seamless with the movements we make. It is where our decision-making stutters that the mental chatter of self-talk breaks through to disrupt, or complete the disruption, of performance. Thus Krein's objection $(2015,275)$ that not all satisfactory sport experience involves internal struggle is true, but not an objection to the position I have argued.

\section{The Sublime}

Krein, I take it, is arguing that nature sports offer a very special kind of intensity. To this point, none of the intensities we have considered are unique to sport, much less to nature sport. What, then, can nature sport offer that other activities cannot? Krein repeatedly emphasises, here and elsewhere $(2014,2007)$, the significance of the environment within which the activity takes place, which is a natural one of 'constantly changing features possessing awe-inspiring amounts of force and size' $(2015,282)$.

"In adventure sports, the other "participant" in the game might be a 10 metre wave, 60 degree couloir, or an 8,000 metre peak, rather than a human competitor. It is my claim that the opportunity to play with such awesome partners is one of the principal sources of the attraction of adventure sports.

'For one who takes sports seriously, the opportunity to take part in sports activities under conditions that make it possible to engage with natural features more powerful than any conceivable human being, is at least worth considering.' (2007, 90-91).

A calmly flowing stream or quiet beech forest would, presumably, not do: we need high mountains, powerfully surging surf, and roaring torrents. Why?

There are two possible answers here. First, that force and size are important for separating the sheep from the goats, or the skilled from the dabblers, the climbers from the hikers. The kind of intensity sought, then, is the sort that can only come in extraordinary environments demanding a high level of skill. There is, however, no reason to suppose that

${ }^{2}$ These are simple and vague examples. Consider the climber who has to decide quickly whether to be 'the one who cut the rope', which could become either 'the one who saved everyone else' or 'the one who killed climber $x$ '. 
Intensity and the Sublime 9

flow intensity is only ever experienced by those who are at the highest level of expertise in an activity, nor that the elite do not struggle physically, nor that flow intensity is experienced as ease. Expertise is gradually obtained and may not be uniform throughout an activity for a given individual (we acquire expertise over time and do some things better than we do others). Flow is a product of competence at one's particular skill level and one may experience it in some parts of one's activity but not others, and one may experience it at a level of challenge optimal for one's own abilities where others might find only discord. Some significant degree of competence is required but there seems little reason to suppose that perfect mastery is. ${ }^{3}$ The second possible explanation for the emphasis on magnitude and force is that these are important because what Krein is concerned with here is the sublime.

The sublime is an important concept in the history of aesthetics generally and especially landscape or environmental aesthetics. Kant's formulation of the sublime in The Critique of Judgement, which in its turn underlies later elaborations by Schiller, Schopenhauer, and others in the nineteenth century, presents the closest parallels and connections with the kind of intense experience to which Krein refers. I stress that Krein does not use this term; consequently, what I present here is speculative.

The sublime, as Kant presents it, is not to be found in nature itself. 'Who', he asks, 'would apply the term "sublime" even to shapeless mountain masses towering one above the other in wild disorder, with their pyramids of ice, or to the dark tempestuous ocean, or such like things?' $(86, \S 26)$. We encounter appallingly powerful natural phenomena and then, taking in the contrast between their size and power and our own in imagination, we feel our physical insignificance. We might at that point feel fear, overwhelmed by a subjective apprehension of our relative smallness and the threat to our continued existence that such objects could represent. There need not be a genuine threat (Brady (2002), 37). Walking a high mountain pass, standing by the side of a thundering waterfall or before a precipitous ravine, looking out from shore at hurricane whipped waves crashing over lighthouse and breakwaters, our

${ }^{3}$ Moreover, insofar as flow is a phenomenological awareness of achieved bodily competence, the question is not whether the subject of the experience is at a predetermined level of achievement, but whether they are having a particular kind of experience of movement, and this is a matter of whether the subject is (a) performing the sort of actions that can generate flow-experiences and (b) whether these are in fact flow-experiences. One can, of course, be deluded about one's experiences. Any claim that is inherently self-contradictory, for example, such as 'I have now achieved a noncognitive state' (which itself reports a cognitive state) is ipso facto mistaken or delusional. If, however, the experience is of the sort 'it seems to me that I am experiencing everything coming together for $\mathrm{me}^{\prime}$, denial of a flow-claim will be a more complex task, since one must deny not only that there is flow but that it could genuinely seem to the subject that they are experiencing it (e.g., one must show that they have misidentified the type of experience they are having). 
imaginations fix for us the mismatch between our own natural powers as individuals and those of nature itself. The realisation that we are mere specks in the cosmos and, in particular, that we lack the capacity to resist such indifferent forces, incites this subjective feeling of awe, admiration, or even panic. But these feelings are not themselves the sublime.

First, because this response is itself a natural one-both in the sense that it is an affective and thus sensuous one and in the sense that it is normal for small defenceless beings to be fearful of their annihilation by enormous and powerful forces if they are aware of them. It is, one might say, the natural way of things. For Kant, however, humans are not only natural beings in the sense that they also have access to the 'supersensuous', which means that they are not tied inevitably to the natural but are capable of self-determination above and beyond the impulse provided by fear or other inclinations. In short, they are rational beings and can determine themselves according to principles of reason. This provides the defining element for the sublime as it is the supersensuous that allows us to resist the force of nature upon us. Reason gives us the means to resist fear, and to understand how this capacity is what not only gives us the means to control what frightens us but to see ourselves as fundamentally more, indeed, superior to, what disturbs us so. As Kant observes,

'Bold, overhanging, and, as it were, threatening rocks, thunderclouds piled up the vault of heaven, borne along with flashes and peals, volcanoes in all their violence of destruction, hurricanes leaving desolation in their track, the boundless ocean rising with rebellious force, the high waterfall of some mighty river, and the like, make our power of resistance of trifling moment in comparison with their might. But, provided our own position is secure, their aspect is all the more attractive for its fearfulness; and we readily call these objects sublime, because they raise the forces of the soul above the height of vulgar commonplace, and discover within us a power of resistance of quite another kind, which gives us courage to be able to measure ourselves against the seeming omnipotence of nature.' [91, §28]

In relation to the vastness of nature we find our own limitation. But we also find in our rational capacity another standard, nonsensuous and infinite, 'and in comparison with which everything in nature is small, and so found in our minds a pre-eminence over nature even in its immeasurability' (92). Just as the hugeness of nature forces the recognition of our natural puniness, our capacity for reason forces the recognition of our capacity to be independent of nature. 'Therefore nature is here called sublime merely because it elevates the imagination to a presentation of those cases in which the mind can come to feel the sublimity of its own vocation over nature' (92). This feeling then gives rise to a pleasure that is both an appreciation of the natural qualities of the environment before us and the result of our recognition that we are removed from it as well. The sublime, then, is not in nature itself, nor in our natural response to its stimuli, but in the further experience that it provokes, namely, our awareness of our separation from and superiority to nature in virtue of our capacity for reason. As Kant puts it, the experience of the sublime 'is a might enabling us to assert our 
Intensity and the Sublime 11

independence as against the influences of nature, to degrade what is great in respect of the latter to the level of what is little, and thus to locate the absolutely great only in the proper vocation of the subject' (99). It is this overcoming of nature and sensibility by moral principles which gives it its interest (102).

There are a number of points of concurrence between Krein's descriptions of nature sport activity and Kant's of the sublime. Obviously, there is the circumstance that the sublime is experienced typically in the encounter with natural features of considerable magnitude and power, but the role given to reason is significant as well. To see this, recall that an important element in flow intensive sport experience is the ability not only to perform certain physical movements well, but to make correct decisions about those movements without losing the flow. Knowledge, skill, and judgement are critical elements in nature sport activity, as they are in the traditional varieties as well. In nature sports, what is required is knowledgeable and well-reasoned decisions about situations, including environmental factors, that could lead to unfortunate consequences if the individual were not able to respond to them in a measured way. In other words, knowledge and sound judgement is what ensures that one is safe even if imagination wanders to what terrible things could possibly occur if one were not. More than that, it is knowing that one is knowledgeable and physically competent at the same time that one is in direct engagement with such natural features that allows for this specific kind of sublime-flow intensity. Reason and self-command over one's abilities and one's affective responses is the basis of the sublime experience and, it would seem, the specific intensity provided by nature sports. Indeed, nature sports of this sort could be described as, in Kant's words, 'measur[ing] ourselves against the seeming omnipotence of nature' $(91, \S 28)$. Schopenhauer's subsequent take on the sublime frames the image of reason or consciousness triumphing over one's bodily nature particularly forcefully: the objects that we contemplate may have a 'hostile relation' to the human will as manifested in our physical form. The sublime is 'that state of pure knowing...obtained first of all by a conscious and violent tearing away from the relations of the same object to the will which are recognised as unfavourable, by a free exaltation, accompanied by consciousness, beyond the will and the knowledge related to it.' This 'exaltation' is experienced when we both acknowledge the possible threat and consciously tear ourselves away from our will, i.e., our concern for our bodies and desires, in order to contemplate what lies before us as a 'pure, will-less subject of knowing' (WWR I §39).

\section{The Sublime and Sport Movement}

Nature sports offer the possibility of the sublime. They are certainly not unique in doing so, however. One need not be doing much of anything to experience the sublime: one could be sitting on a bus being driven through high mountains or on an airplane flying through a particularly nasty thunderstorm. Moreover, if we follow Kant, it seems clear that traditional sports can offer such experiences as well-Kant's example of war makes it evident that, although natural features are the typical catalyst, human conflict is sufficient. Kant's point is that while real danger is not required for an experience of the sublime, it may also be found where it is real, and this underscores his contention that what matters is the resistance we are 
Intensity and the Sublime 12

able to put up to the persuasive effects of our inclinations. The soldier finds his courage to control his fears, and in this self-overcoming encounters sublimity (93). ${ }^{4}$ Hence, it is not unreasonable to suppose that, if the sublime can be found in warfare, it does not depend on scenic natural vistas as we understand them, but might also be encountered in more traditional, if especially fraught, sporting arenas, such as Olympic competition, Cup finals, etc.

While the sublime as such cannot be what differentiates nature sport from the traditional variety, what Krein commits himself to is the view that nature sport offers a combination of things: first, a particular kind of intensity, namely an experience of (what amounts to) the sublime that is a consequence of interaction with specifically natural environments, combined with the intensity that is the result of a skilled and knowledgeable physical activity conducted in this sort of natural environment and, further, an absence of interhuman competition. That intensity, or sublimity of experience, is generated by a specific environmental interaction: being able to dynamically interact with extraordinary natural features.

What Krein's picture of nature sport offers us that a more traditional conception of the sublime as an aesthetic ideal does not is a preference for being active in the land and waterscapes that generate the sublime, rather than simply gazing at it from a secure viewpoint outside the natural scene. In an earlier paper (2014), Krein offers a number of illustrations of what he means by 'interaction' and here it is clear that this is a careful response to some set of environmental elements in order to have an optimal athletic experience, e.g.,

'In surfing, an athlete paddles into a wave and rides it. The wave is moving and constantly changing and the surfer works with the wave with the goal of getting the best ride. In such situations, the surfer is working with the wave as a figure skater might work with his or her partner. Rather than another human being, the wave being surfed plays the primary role of a teammate as I have described it.' $(2014,194)$

'The whitewater kayaker, like the surfer, interacts with moving water. Only, in the case of the kayaker, it is water in a river that provides a partner for the paddler to work with.' $(2014,195)$

What is important is the physical and mental challenge to the athlete generated by

${ }^{4}$ Unlike Kant, Schopenhauer suggests that the sublime would not survive real danger: 'If a single, real act of will were to enter consciousness through actual personal affliction and danger from the object, the individual will, thus actually affected, would at once gain the upper hand. The peace of contemplation would become impossible, the impression of the sublime would be lost, because it had yielded to anxiety, in which the effort of the individual to save himself supplanted every other thought.' (WWR I, §39). 
Intensity and the Sublime 13

natural features and the competence of the athlete in countering them, and what matters about those features is their power, size, and relentlessness, presumably because of the challenge they present to the athlete. This challenge and the skill of the athlete combine to produce an intensity of experience that appears largely equivalent to the sublime. There are, however, some aspects of this ideal of intensity that may give us pause. I shall here mention two that I consider important and damaging, namely, aesthetic elitism and anthropocentrism.

Fixing on the sublime as a defining feature of nature sport severely limits what could count as nature sport in a way that is not ultimately defensible. Many natural environments and our days out in them, while possessing qualities of considerable interest, fall short of generating the sublime. If it is a defining characteristic of 'nature sport' that it involve interactions with natural features of a magnitude to be susceptible of sublime experiences, then the criterion runs the risk of imposing an aesthetic elitism that would, I think wrongly, invalidate much sport in nature, including much nature oriented sport, as 'nature sport'. If nature sport only qualifies as such where conditions are of this extreme character, a level of athletic elitism is imposed on participation in nature sport (because of the very high levels of sport competence required to carry out these activities with any hope of success or safety)-and such a restriction-by-definition is unjustly exclusive. There is no obvious reason why a strenuous and demanding paddle around an otherwise ordinary northern lake, or a long and gruelling ski through a particularly tedious valley, would not qualify as nature sport although neither is likely to qualify as sublime. In addition, such a conception commits a kind of aesthetic elitism by valorising as aesthetically worthy only the gaudily gigantic. Why see the value of natural features for dynamic sport interaction only in terms of the huge and powerful? Concentrating on the sublime neglects other important and aesthetically compelling features of natural environments, such as complexity, delicacy, balance, and environmental (and historical) importance within a region. While the environment through which one moves may not generate the sublime, it may still have a wealth of natural interest to reveal, and it may still need to be navigated with skill and delicacy, at the same time as one engages in a demanding physical task. We do not only have aesthetically intense sporting experiences in interaction with huge and powerful objects; sometimes, a quiet stream will do.

The issue of anthropocentrism ${ }^{5}$, moreover, is clearly related to that of aesthetic elitism in that we need to question what we get out of the interaction with huge natural features-the sublime, yes, but to what extent is that experience one of nature or of the human? Certainly, if we follow Kant on the matter, the sublime isn't about those extraordinary natural features at all, but about us confronting them and coming out reinforced in our sense of human

${ }^{5} \mathrm{By}$ 'anthropocentrism' I here mean: concerned with the human either without regard to the nonhuman or responding to human interest at the expense of possible nonhuman interests. I do not deny that humans see things from their specific perspective, nor assume that it is a bad thing that they do. 
Intensity and the Sublime 14

superiority and transcendence over the natural; for that matter, these natural features have only an instrumental significance in relation to this moral project. As interactions with the deep richness of the natural world go, this is relatively impoverished. The interaction with natural features central to nature sport, I suggest, need not be limited to the extremities of magnitude but could and perhaps should, include attention to the small and the quiet as well. What a striving for the sublime and the wide-screen dramatic vista does is blind us to the small and no less wonderful things close beside us. Likewise, concentrating on girding ourselves to overcome our natural impulses doesn't necessarily enhance our openness to recognising the ways in which we share nature with the many other objects and beings we encounter in wilder spaces. Listening, reflecting, noticing, are smaller scale interactions that allow others to inform us of who or what they are about distinct from our own projects and is as worthwhile in our relations with nature as with other humans: encounters with natural features need not only be about us.

\section{Intensity as a Disclosure of Being}

Krein's description of nature sport is, as formulated, too restrictive. The emphasis on natural features of great magnitude imposes an aesthetic elitism that is unnecessary and unreasonably limiting of the category of nature sport. Moreover, the emphasis on intensity of experience in these situations entrenches an anthropocentrism that inhibits experience of the natural features with which one interacts. What an emphasis on sublime-inducing situations also enforces is a requirement for advanced technical skill that makes nature sport inaccessible for most would-be practitioners. That is, it would seem to follow that unless one can perform at a very high level in the sport one is not actually doing the sport. This seems counterintuitive. A sub-Olympic standard volleyball player is still a volleyball player, so there seems no reason to say that a climber of modest or boring mountains is not a climber or not engaging in nature sport.

Remember that we began with a conception of intensity in sport that centred in the experience of being fully present in the flow of activity and movement. This presence involves giving one's full attention to the activity and to the environment within which the activity is taking place. Focussing our attention on something usually means that we withdraw it from something else. Athletes tend to be quite good at focussing attention, but this is normally on themselves and a select and narrow band of immediate objects outside themselves upon which they act. The athlete thus aims at being subject-active in a fairly extreme way. A different and no less rich intensity can be had by shifting that focus further outside the self and its interests, by redirecting attention to environmental objects and creatures with a view to inviting a disclosure of their own being, ${ }^{6}$ instead of using them primarily as catalysts or props in one's personal voyage of transcendence. The natural world is not for us any more than other humans are. Those against whom we compete in a hockey or football game do not have their

${ }^{6}$ I borrow this term from Simone de Beauvoir (1991). 
Intensity and the Sublime 15

meaning solely in their significance for our own performance; neither do objects and organisms in the natural environment. ${ }^{7}$ What nature sports could offer its practitioners that would be unique is not the sublime but the revelation of the being of the natural world that extends through and beyond ourselves, if we would just pay more attention to it. We already, in acting athletically, express our naturalness, revel in our physical and animal capacities; we might also in doing so explore how we intersect with other-nature. Thus, a nature oriented sport offers us a sporting experience of no less intensity than that offered by the active-sublime, but one more broadly democratic in its aesthetic possibilities in that it offers accessibility beyond what might otherwise be restricted to an athletic elite and in the sense that its intensity does not require the anthropocentric drama of the sublime.

${ }^{7} \mathrm{I}$ am aware that some would contest this claim. 
Intensity and the Sublime 16

\section{References}

Brady, Emily. (2003). Aesthetics of the Natural Environment. Tuscaloosa, Alabama and Edinburgh: University of Alabama Press and Edinburgh University Press Ltd.

de Beauvoir, Simone. (1991). The Ethics of Ambiguity. Bernard Frechtman (trans.). New York: Carol Publishing Group.

Howe, Leslie A. (2008). 'On Competing Against Oneself, or "I need to get a different voice in my head."' Sport, Ethics, and Philosophy. Vol. 2, no. 3: 353-366.

. (2012) . 'Different Kinds of Perfect: The Pursuit of Excellence in Nature Based Sports.' Sport, Ethics, and Philosophy, 6, 3: 353-368.

Jaeger, Suzanne. (2006). 'Embodiment and Presence', in David Krasner and David Z. Saltz (eds). Staging Philosophy. University of Michigan Press: 122-141.

Kant, I. (2007). Critique of Judgement. James Creed Meredith (Trans). Nicholas Walker (Ed.). Oxford: Oxford University Press.

Krein, Kevin. (2007). 'Nature and Risk in Adventure Sports'. In McNamee, Mike (Ed.) Philosophy, Risk, and Adventure Sports. London: Routledge, 2007: 80-93.

. (2014). 'Nature Sports'. Journal of the Philosophy of Sport 41, 2: 193-208.

. (2015). 'Reflections on Competition and Nature Sports'. Sport, Ethics, and Philosophy 9, 3: 271-286.

[No author]. (1971). The Compact Edition of the Oxford English Dictionary. Oxford: Oxford University Press.

Schopenhauer, Arthur. (1969). The World as Will and Representation. E.F.J. Payne (Trans). New York: Dover Publications, Inc. 